Concept Paper

\title{
Spatial Relation between Wind Stress and Storm Surge during Hurricanes Laura and Delta in 2020
}

\author{
Shih-Ang Hsu * \\ Coastal Studies Institute, Louisiana State University, Baton Rouge, LA 70803, USA; E-Mail: \\ sahsu@lsu.edu
}

* Correspondence: Shih-Ang Hsu; E-Mail: sahsu@lsu.edu

Academic Editor: Zed Rengel

Adv Environ Eng Res

2021, volume 2, issue 3

doi:10.21926/aeer.2103022
Received: July 25, 2021

Accepted: August 31, 2021

Published: September 02, 2021

\begin{abstract}
Spatial relation between wind stress and storm surge during two hurricanes in 2020 is investigated. It is found that, during Laura's landfall, the area inside of 65 knots (34 m s${ }^{-1}$ ) isotach or line of equal wind speed can produce up to $18 \mathrm{ft}(5.5 \mathrm{~m})$ inundation and during Delta, the area inside of 50 knots $\left(26 \mathrm{~m} \mathrm{~s}^{-1}\right)$ up to $11 \mathrm{ft}(3.3 \mathrm{~m})$ high water level above the ground. The tropical cyclone (TC) surface analysis near landfall by the Regional and Mesoscale Meteorology Branch (RAMMB) is recommended as a first approximation for coastal environmental and engineering applications during a TC.
\end{abstract}

\section{Keywords}

Overwater wind stress; storm surge; Hurricane Laura (2020); Hurricane Delta (2020); RAMMB products

In 2020 Hurricanes Laura and Delta devastated southwest and south central coasts of Louisiana (LA), see Tropical Cyclone (TC) Reports by the National Hurricane Center (www.nhc.noaa.gov) [1, 2], respectively. Based on these reports, storm surge is defined as the water height above normal astronomical tide level and estimated inundation is the maximum height of water above ground.

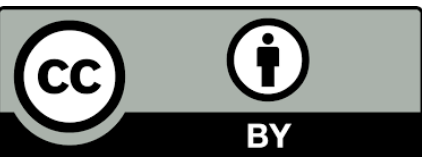

(C) 2021 by the author. This is an open access article distributed under the conditions of the Creative Commons by Attribution License, which permits unrestricted use, distribution, and reproduction in any medium or format, provided the original work is correctly cited. 
According to the National Weather Service (NWS) Office in Lake Charles, LA, as shown in Figure 1 and Figure 2, the inundation was up to $18 \mathrm{ft}(5.5 \mathrm{~m})$ for Laura and to $10 \mathrm{ft}(3 \mathrm{~m})$ for Delta, respectively. During a TC, the Regional and Mesoscale Meteorology Branch (RAMMB) of NOAA/NESDIS issues a Multi-Platform TC Surface Wind Analysis once in every 3 hours worldwide. The isotach (equal wind speed line) maps near landfall during Laura and Delta are presented in Figure 3 and Figure 4, respectively.

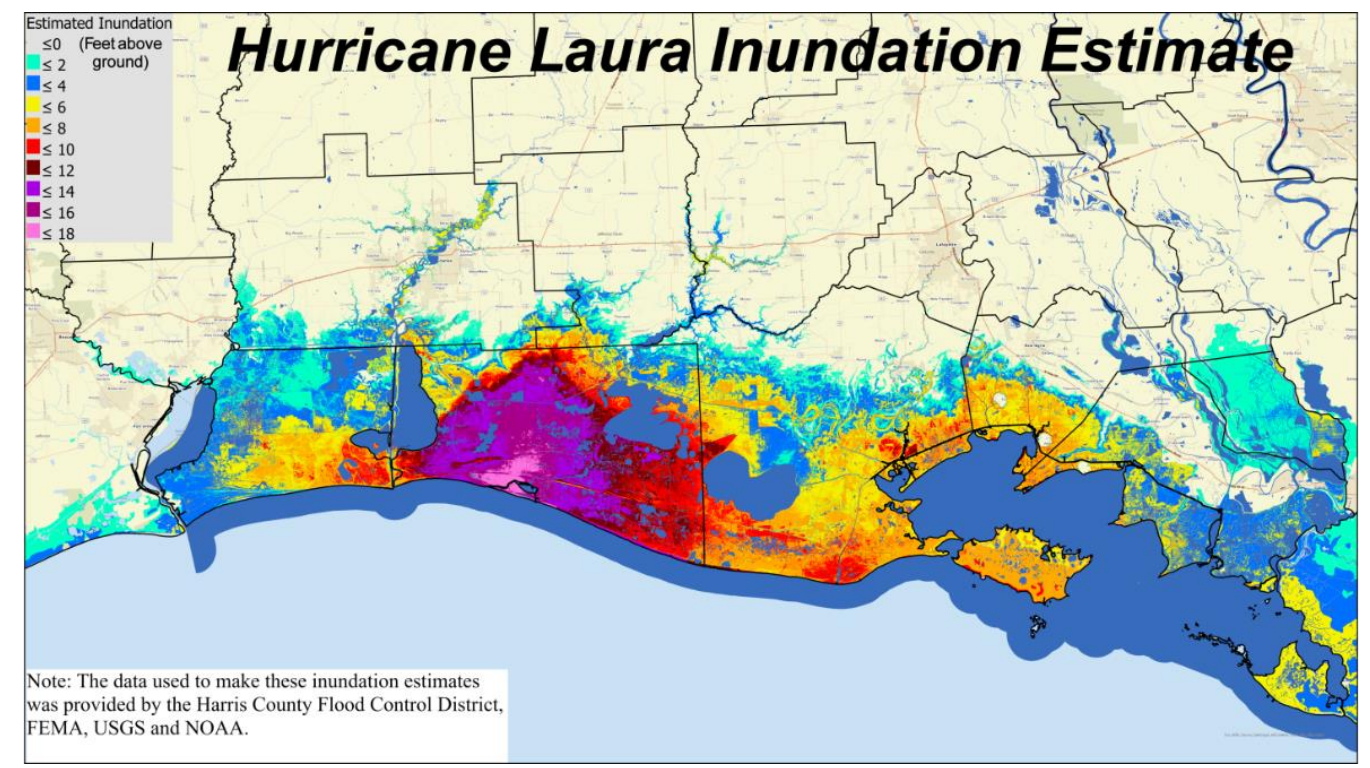

Figure 1 Estimated inundation height in southwest LA impacted by Hurricane Laura in 2020 based on https://www.weather.gov/images/lch/events/2020Laura/SW\%26SCLouisiana.png.

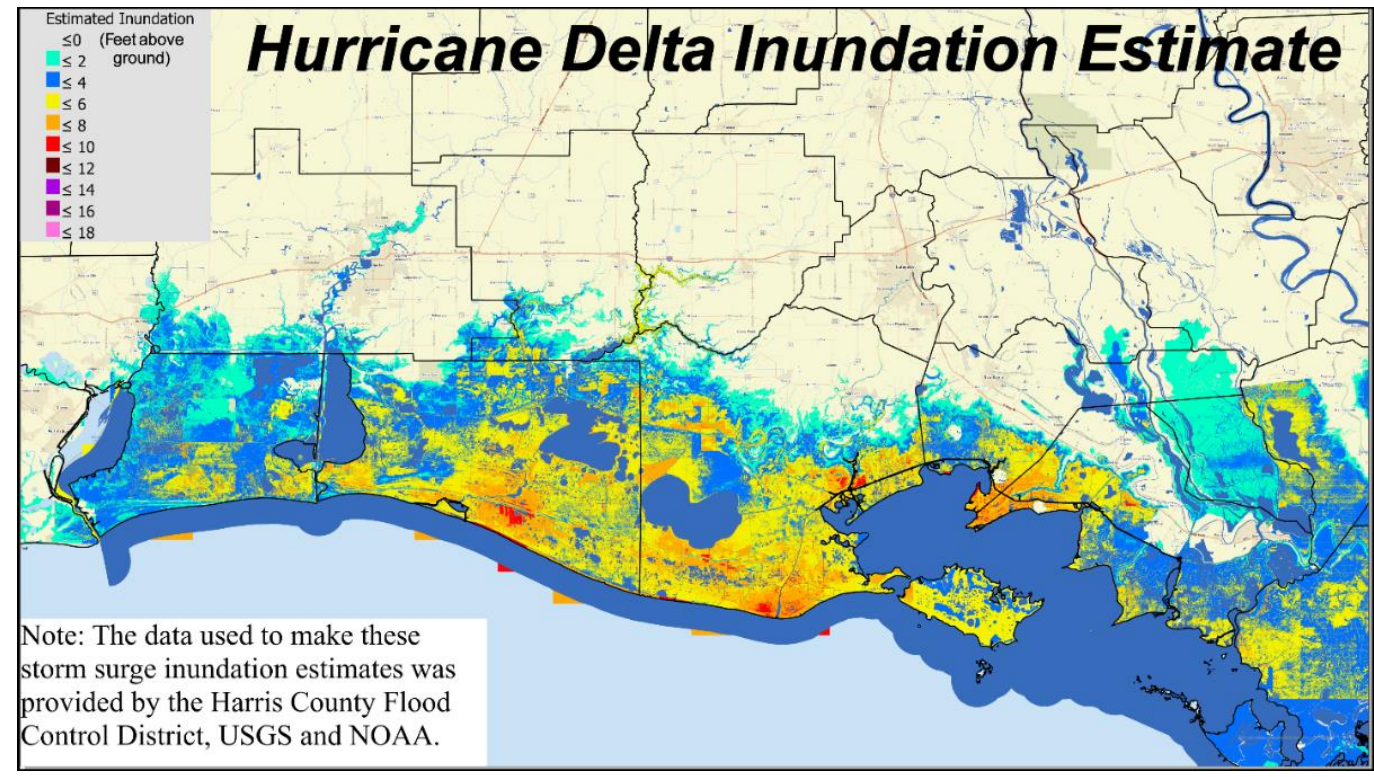

Figure 2 Estimated inundation height in south central LA impacted by Hurricane Delta in 2020 based on https://www.weather.gov/images/lch/events/2020Delta/SW\%26SCLouisiana.png. 


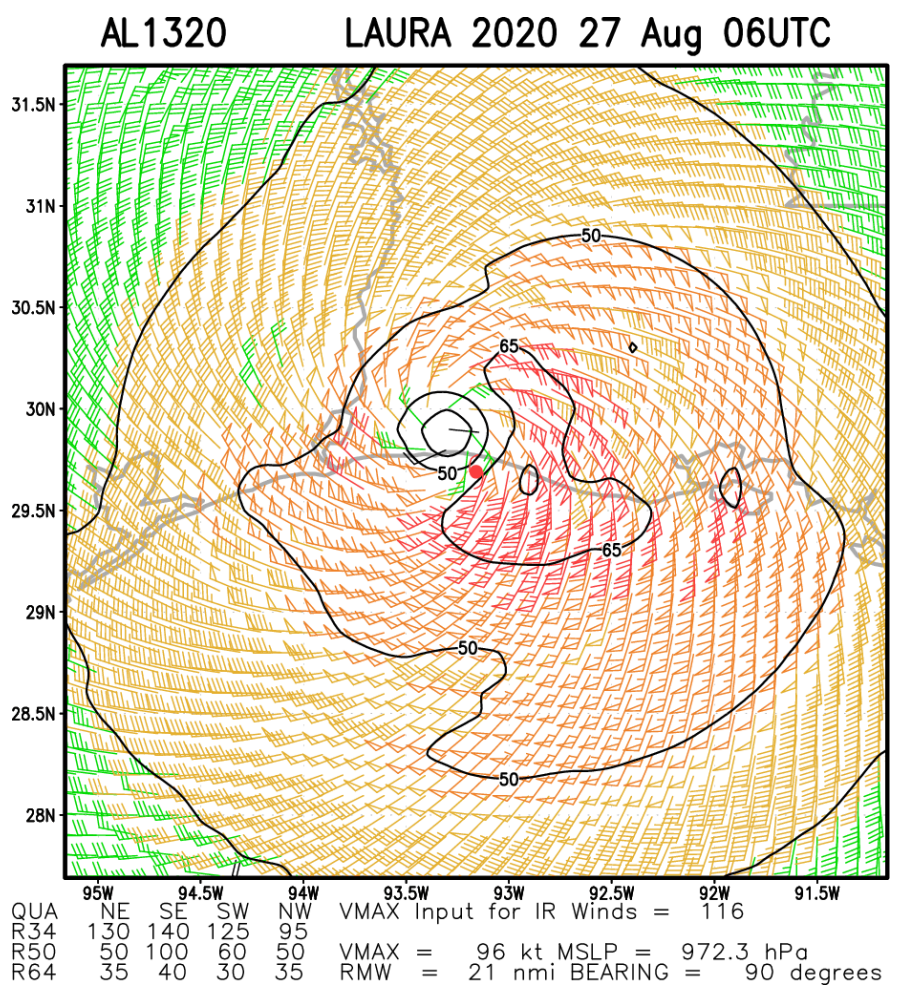

Figure 3 An isotach map near Laura's landfall at southwest coast of LA at 06UTC on 27 August 2020 based on https://rammbdata.cira.colostate.edu/tc_realtime/image_mpsatwnd.asp?product=mpsatwnd\&storm _identifier=al132020\&product_filename=2020al13_mpsatwnd_202008270600.

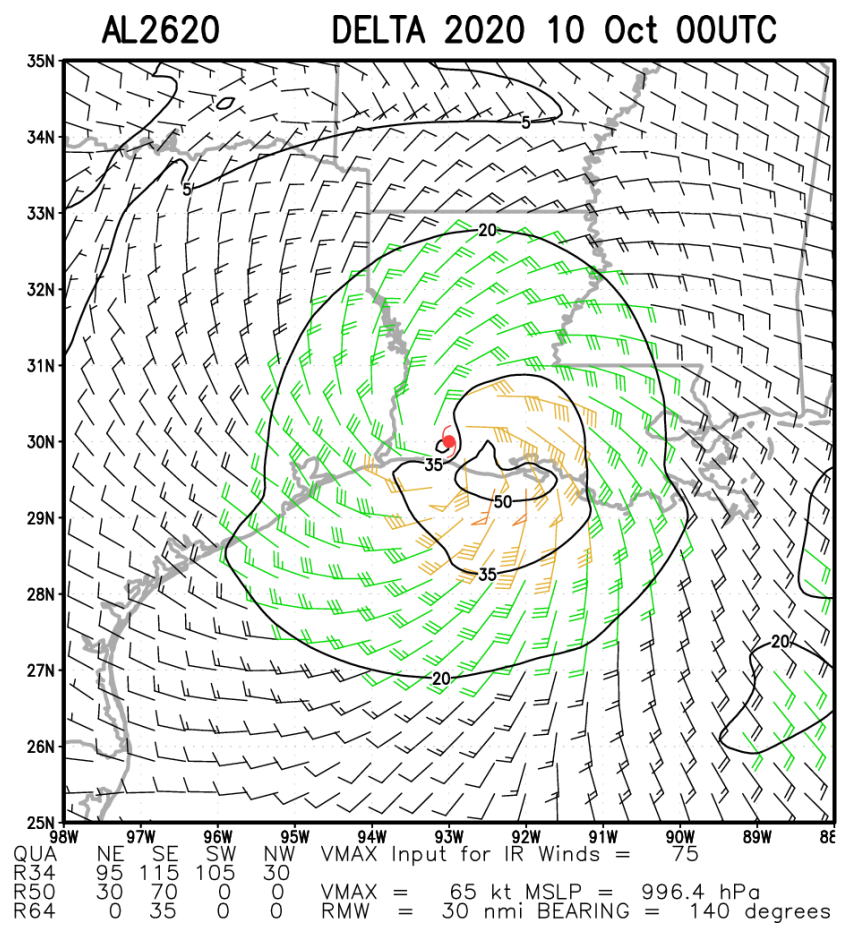

Figure 4 An isotach map near Delta's landfall at south central coast of LA at O0UTC on 10 October 2020 based on https://rammbdata.cira.colostate.edu/tc_realtime/image_mpsatwnd.asp?product=mpsatwnd\&storm _identifier=al262020\&product_filename=2020al26_mpsatwnd_202010100000. 
According to Hsu $[3,4]$, most storm surges can be explained by the effect of wind stress using $\mathrm{S}$ $=0.005 \mathrm{~V}^{2}$, here $\mathrm{S}$ is the storm surge in meters and $\mathrm{V}$ is the wind speed in $\mathrm{m} \mathrm{s}^{-1}$. From Figure 3 , the area inside of 65 knots $\left(34 \mathrm{~m} \mathrm{~s}^{-1}\right)$ isotach should have experienced up to $5.6 \mathrm{~m}$ or $18 \mathrm{ft}$ storm surge. This is in reasonable agreement spatially with the area inside of $14 \mathrm{ft}$ inundation line if we add a few feet of topography. Similarly, from Figure 4, the area inside od 50 knots $\left(26 \mathrm{~m} \mathrm{~s}^{-1}\right)$ isotach should have the storm surge up to $3.3 \mathrm{~m}$ or approximately $11 \mathrm{ft}$. Again, this is in fair agreement with the area inside of $10 \mathrm{ft}$ inundation line. Therefore, it is concluded that the isotach map near a TC's landfall may be useful for coastal environmental and structural engineering applications. Note that improvements may be made that if the GIS (geographic information system) used by NWS and RAMMB can be unified.

During the review process, three questions were raised: the first one is related to the validity of the wind-stress tide equation, i.e., $\mathrm{S}=0.005 \mathrm{~V}^{2}$. A verification of this formula is presented in Table 1 based on the information provided by Figure 4 and Figure 5 and Cangialosi et al. (2020, page 17). Because the National Ocean Service (NOS) station at FRWL1 was damaged by Laura, 3 NOS stations during Delta are employed. Note that, according to Cangialosi et al. 2020, since the storm surge as listed in the last column of Table 1 is the measured water height above normal astronomical tide level which is consistent with that of computed wind-stress tide value, our proposed method is reasonable. The second question is related to the wind direction and storm surge, the answer is provided in Figure 4 and Figure 5 that all three stations as listed in Table 1 had onshore wind direction, indicating that the storm surges were induced by the direct onshore flow. The last question is related to the effect of astronomical tide on the storm surge. The answer is provided in Cangialosi et al. (2020, page 17) that the difference between storm surge and storm tide in our study area is $(9.45-9.39)=0.06 \mathrm{ft}$ for FRWL1 and $(6.40-6.44)=-0.04 \mathrm{ft}$ for AMRL1, indicating the effects of astronomical are small during Delta. Note that the storm tide is water height above the North American Vertical Datum of 1988 (NAVD88).

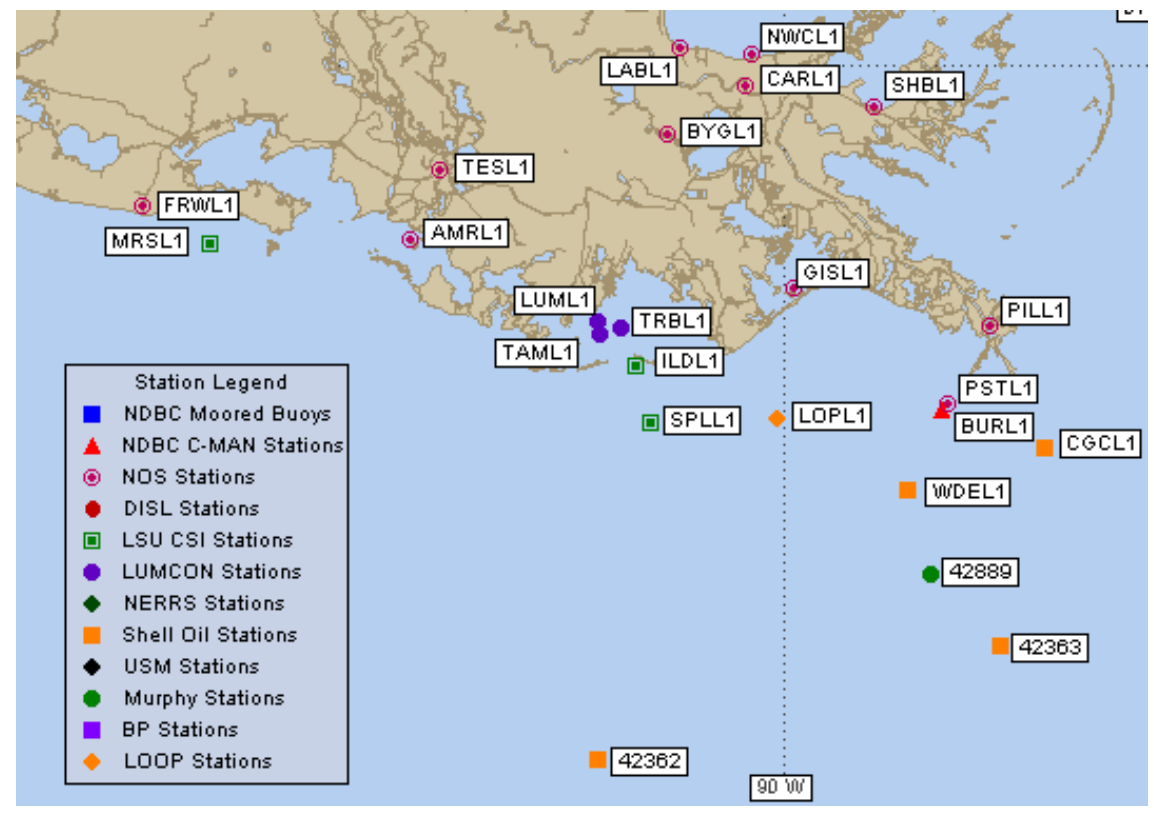

Figure 5 Location map from the National Data Buoy Center (NDBC) for the National Ocean Service (NOS) stations at FRWL1, AMRL1 and GISL1 used in Table 1. See https://www.ndbc.noaa.gov/images/maps/WestGulf_inset.gif. 
Table $1 \mathrm{~A}$ verification of the wind-stress tide equation during Hurricane Delta in 2020 (Data source: Cangialosi et al. 2020, Table 3 for National Ocean Service (NOS) Sites in Louisiana).

\begin{tabular}{|c|c|c|c|c|c|}
\hline $\begin{array}{l}\text { Stations } \\
\text { See Figure } 5\end{array}$ & $\begin{array}{l}\text { U10, knots } \\
\text { from Figure } 4\end{array}$ & $\begin{array}{l}\mathrm{U} 10 \\
\mathrm{~m} \mathrm{~s}^{-1}\end{array}$ & $\begin{array}{l}\text { Wind-stress } \\
\text { Tide, } \mathrm{m}\end{array}$ & $\begin{array}{l}\text { Wind-stress } \\
\text { Tide, } \mathrm{ft}\end{array}$ & $\begin{array}{l}\text { Storm surge } \\
\mathrm{ft} \text {, measured }\end{array}$ \\
\hline FRWL1 & 50 & 25.8 & 3.3 & 10.8 & $9.5^{*}$ \\
\hline AMRL1 & 35 & 18.0 & 1.6 & 5.3 & 6.4 \\
\hline GISL1 & 20 & 10.3 & 0.5 & 1.6 & 1.6 \\
\hline
\end{tabular}

*This data is from a temporary station that was installed at Freshwater Canal Locks (FRWL1) before Delta. The sensor reached its physical limit, and the peak water level may have been higher than these measurements.

\section{Acknowledgments}

Maps, charts and datasets provided by the NWS Office in Lake Charles, LA, the RAMMB, NHC, NDBC, and NOS used in this brief report are greatly appreciated.

\section{Author Contributions}

The author did all the research work of this study.

\section{Competing Interests}

The authors have declared that no competing interests exist.

\section{References}

1. Pasch RJ, Berg R, Roberts DP, Papin PP. Tropical cyclone report, Hurricane Laura, 2020. MiamiDade County, FL: National Hurricane Center; 2020; AL132020.

2. Cangialosi JP, Berg R. Tropical cyclone report, Hurricane Delta, 2020. Miami-Dade County, FL: National Hurricane Center; 2021; AL262020.

3. Hsu SA. Storm surges in New York during Hurricane Sandy in 2012: A verification of the windstress tide relation. Boundary Layer Meteorol. 2013; 148: 593-598.

4. Hsu SA. Storm surge measurements in Naples, Florida, during Hurricane Irma in 2017. Mar Weather Log. 2017; 61: 61-62. 


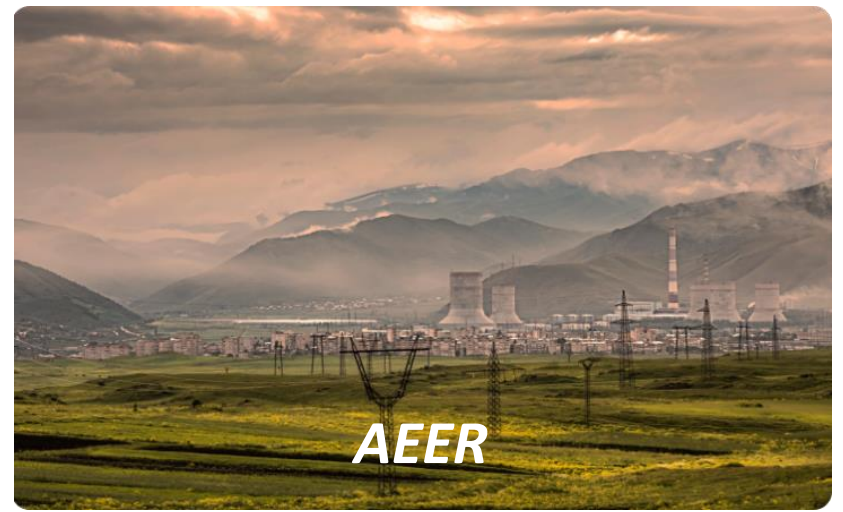

Enjoy AEER by:

1. Submitting a manuscript

2. Joining in volunteer reviewer bank

3. Joining Editorial Board

4. Guest editing a special issue

For more details, please visit:

http://www.lidsen.com/journals/aeer 